\title{
Finger Print Analyze (Health by Birth Knowing Through Finger Impressions)
}

\author{
Venkateswara Rao Madduru \\ Finger Print Expert, Inspector of Police, F P B. CID, District Police Office, Kurnool. Andhra Pradesh. India
}

\begin{abstract}
I am an expert in the arena of dermatoglyphics i.e. study of finger prints. On this discipline, I have an experience of 28 years. Consequently I have done some research work in the formation of Patterns on the first phalange of all the fingers and also on the skin of palms. By authenticating the finger impressions and its nature of forming ridge characteristics, ridges as well as its patterns, I have understood that each finger impression is working as an index of an organ which leads to the analysis of organ development and its condition. For declaring this statement, I have verified thousands of finger impressions formed at first phalange of fingers.

Keywords: Health By Birth, Finger Impressions, Human Organs, Arches, Loops, Whorls.
\end{abstract}

\section{Evolution of Finger Prints}

Finger Print patterns formed at first phalange of Fingers forming an evolution type i.e., Changes at Womb simultaneously according to the Organs. So parallel changes of Organs as well as Finger Impressions. On analyzing the finger impressions we can found the Organs development and its condition. Finger Print Patterns are formed on the bulb of the first phalange of the fingers as just they are reference of the Organs.

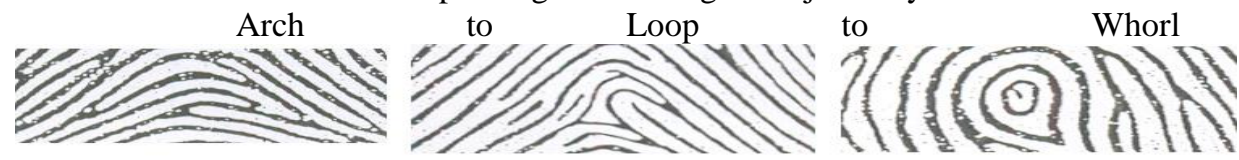

\section{Latest Information}

Latest developments in the field of science have stated that each finger is associated with various human organs. At the time of birth we can be aware of the human organ development and its issues by means of finger print patterns formed in the first phalange of fingers. Through this linking, I have accomplished a number of tasks in our place and given some suggestions for maintaining the organs.

\section{Organs and its Health Groups}

Group -1:15 to 20 Percent of People have no resistance against virus.

(Having the patterns of Arches)

Group-2:65 to 70 Percent of People have some resistance against virus.

(Having the patterns of Loops)

Group-3:15 to 20 Percent of People have resistance against virus.

(Having the patterns of Whorls)

Group-4: between Group - 1 and Group-2

(Having the patterns of combined Arches and Loops)

Group-5: between Group-2 and Group-3

(Having the patterns of combined Loops and Whorls)

Group-6: People with under developed organs (Body Organs Construction)

(Having the patterns of Arches formed only straight flattered Lines)

Group-7: People with incorrect organ development (Reverse Organ Construction)

(Having the patterns of any pattern with converging ridges)

Now a day's people are not maintaining their organs properly. Therefore, it will be extremely useful to the Public. If a person knows which group he belongs to then he/she will take care of their health. This is achievable by verifying finger impressions.

\begin{tabular}{lll} 
Brain & Incapable & Capable \\
Bladder /Sex & No Strength & General \\
Kidneys & No Strength & General \\
Pancreas & No Strength & General \\
\hline
\end{tabular}

IV. Organs Extraordinary More Strength More Strength More Strength
No Problem

No Problem

No Problem

No Problem
Problem

Problem

Problem

Problem 


$\begin{array}{llllll}\text { Heart } & \text { No Strength } & \text { General } & \text { More Strength } & \text { No Problem } & \text { Problem } \\ \text { Stomach } & \text { No Strength } & \text { General } & \text { More Strength } & \text { No Problem } & \text { Problem } \\ \text { Liver } & \text { No Strength } & \text { General } & \text { More Strength } & \text { No Problem } & \text { Problem } \\ \text { Spleen } & \text { No Strength } & \text { General } & \text { More Strength } & \text { No Problem } & \text { Problem } \\ \text { Lung } & \text { No Strength } & \text { General } & \text { More Strength } & \text { No Problem } & \text { Problem }\end{array}$

We can analyze all the above through finger impressions of Ten from Right Thumb to Left Little.
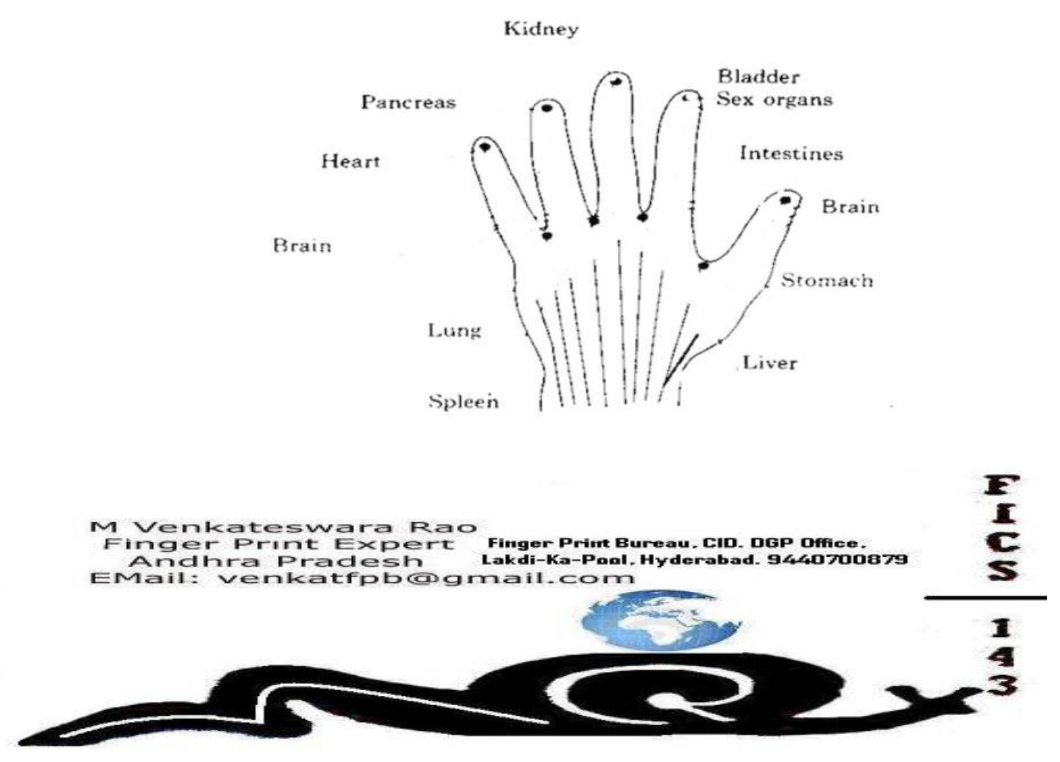

\section{Finger Impressions Conversion System:}

Identifying a person through finger impressions at present has a method of storing entire image and then retrieving that for identifying a person an uniquely, which is complex. At Present the database required for each person to maintain 10 fingers database in the same manner for all the population of India required memory is $120,00,00,000 \times 2500 \mathrm{~KB}$. With this database the comparison of finger impressions take's maximum time. Hence the conversion method helps us to maintain all the information about person in a single folder.

\section{Single Finger Information:}

Here single finger is sufficient to get unique identification number. String to String comparison is very easy and fast even though the data is about 120 cores X 24 X 8 Bits. We are proposing a novel method which stores the characteristics of termination \& bifurcations of a finger impression and form unique identification number code. This unique identification number code can be stored and retrieved for further processing.

\section{Finger impression science:}

The Pioneer's in Finger Print Science had given valuable and evergreen thesis to the World. Through the Finger Prints Science and with the latest technology number of Software Program's are developed and implemented for various requirements to full fill human essentials. One of such requirement is to identify a person through finger impressions is easier and cheaper. This finger impression technology can be used in many areas one such application is controlling of human transportation.

Finger impressions are formed in the first phalange of a finger from right thumb to right little and from left thumb to left little 10 fingers having ridge characteristics (UNIQUE) with patterns. With these unique ridge characteristics we can form unique Number. We need an easy method for identifying a person. The identification is possible through forming unique identification number. So far developed software is used at limited organizations for limited purpose. Why it is limited, because data of finger impressions takes high storage space and everywhere required a Finger Print Expert to comparison and for results. Time Factor due to this problem the software users are lower than the actual users. If the information retrieved at any place users will be benefited.

\section{Advantages:}


Unique identification number can be obtaining for each person through finger impression. Search Process is faster for identifying a person. With this string to string comparison the information about a person will be retrieved within seconds from the database. With this unique identification number we can avoid duplication. This UNIQUE identification number will never change even we scan the finger ' $N$ ' Number of times. The Police Department can use this Software for identifying a criminal. Prevention is possible through this UNIQUE Identification Number. No two fingerprints are identical unless they are made by the same finger of the same person. No two finger prints "UNIQUE Identification Number" are identical unless they are made by the same finger of the same person.

With this concept developed a program In Visual Basic can be able to understand how the Finger Impression converted to a Numerical Value and with that Numerical String how can we go for Tracing a Person Information from Website. The Software was developed in VB.Net.

Present the Finger Impressions influencing in more activities and getting good result with our concept we can increase the utility of Finger Impressions in Business and for Security. The comparison of finger impressions is in a different way. So far it was not developed in the World. No doubt it is INVENTION. Every Human being covered under this concept. Through Characteristics we can generate unique IDENTIFICATION NUMBER. Through this number we can avoid duplication. And we can get whatever the information of a person from website. And also we can use this UNIQUE ID number in all transactions either Government issues or Private Maintenance.

8.1 Main Advantage: Identification of a person from anywhere to any person is possible through one finger impression without delay from the website by using this software device. No need of Plastic Cards for Identity Proof. No need of Finger Print Expert for Comparison and conclusion. In this report a method for unique identification number was proposed unique identification number can be obtaining for each person through his finger impression. Finger impression characteristics termination \& bifurcations form UNIQUE number identification code. This UNIQUE identification number code can be stored and retrieved for further processing. The method was successfully discussed above and implemented in software in VB.Net.

The above method is used to identify a person. Search Process for identification is made easy and fast using this string to string comparison the information about a person will be retrieved within seconds from the database. With this proposed method we can allot unique identification number to each person. The advantage of this method is to avoid duplicate records. Visit: www.healthbybirth.com
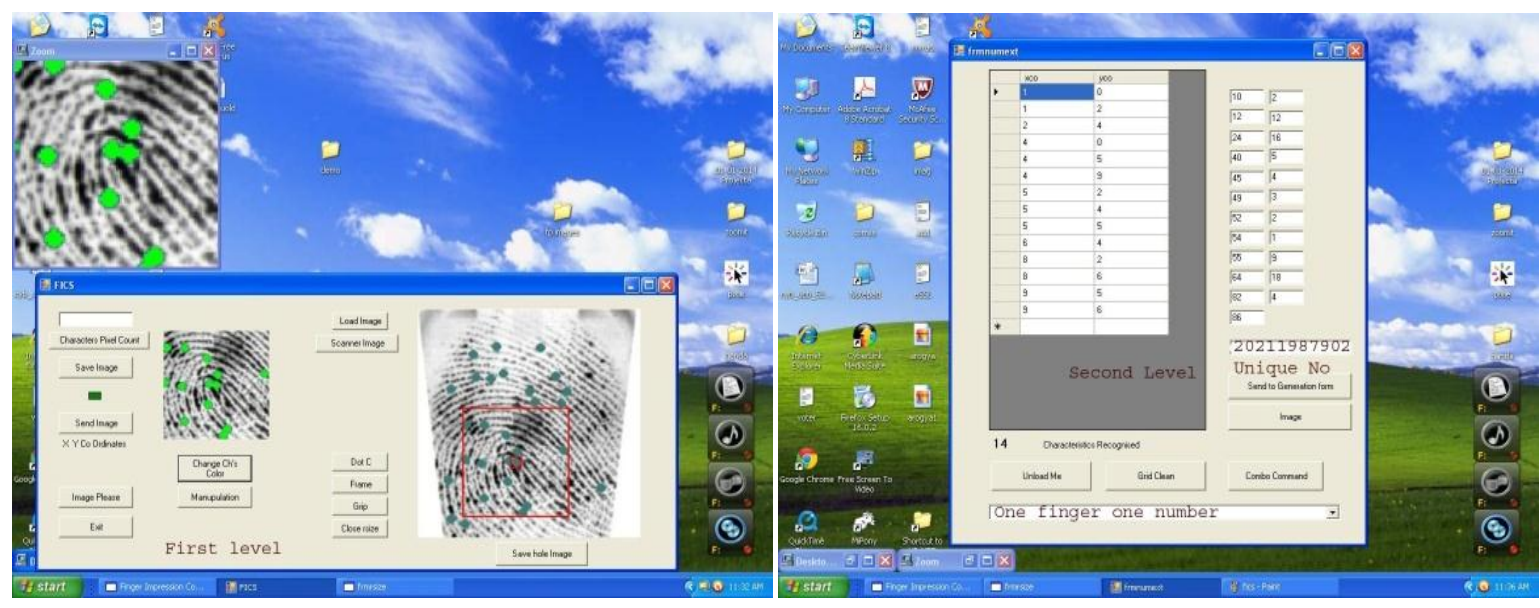